\title{
TORULOSIS ASSOCIATED WITH HODGKIN'S DISEASE
}

\author{
BY \\ K. A. MISCH \\ From the Department of Pathology, Lister Hospital, Hitchin, Herts.
}

(RECEIVED FOR PUBLICATION DECEMBER 1, 1954)

Infections due to Cryptococcus neoformans, a pathogenic yeast causing the disease torulosis, have been reported infrequently in Britain, but are more common than the 10 cases so far published would suggest (Symmers, 1953). Torulosis is a worldwide disease and is endemic in Britain. The association of this infection with Hodgkin's disease has been reported previously (Gendel, Ende, and Norman, 1950), but its apparent rarity in Britain is the reason for presenting an example of recent occurrence.

\section{Case History}

A 41-year-old man, a cardboard blocker by trade, was admitted to the Prince of Wales Hospital, London, on December 1, 1949, complaining of weakness and loss of energy for three months. Just before admission he had noticed swelling of the ankles, and had developed an unproductive cough. His previous health had been good and his weight stationary. He had not resided outside the United Kingdom, apart from two years of Army service in north-west Europe, since 1944.

On examination he was found to be a normally developed man, although somewhat spare and pale. His temperature and pulse rate were normal. His tongue was smooth. There was some abdominal distension and the liver was palpable over three fingerbreadths below the costal margin. The spleen could not be felt, nor any enlarged lymphatic glands. The urine contained a trace of albumin. There was a normochromic anaemia (Hb 9.4 g. \%) and a leukopenia (1,300 white cells per c.mm., of which $56 \%$ were polymorphs, many of them young cells). Sternal puncture showed active normal marrow. Serum was low in total protein $(5.4 \mathrm{~g}$.\%) with a normal albuminglobulin ratio, high alkaline phosphatase (33 unitsJenner and Kay), and normal flocculation reactions (colloidal gold, thymol turbidity, and Takata Ara tests). The erythrocyte sedimentation reaction was within normal limits. The Paul-Bunnell test and the Wassermann reaction were negative. $X$-ray examinations of the chest, alimentary tract, and skeletal system were normal. The temperature, which at first showed small irregular elevations up to $100^{\circ} \mathrm{F}$. $\left(37.8^{\circ}\right.$ C.), gradually became remittent. Repeated blood cultures incubated for six weeks were sterile, and Widal and brucella agglutination tests were negative. There was no response to treatment with penicillin, streptomycin, vitamin $\mathbf{B}_{12}$, or proteolized liver. Only blood transfusions brought about clinical improvement, but this was temporary.

After three months' observation, the spleen became palpable, and small discrete rubbery glands were noted in the right groin, one of which was removed for histological examination. This was a small, grey, soft lymph node almost completely replaced by a follicular granulomatous reaction, superficially resembling tuberculosis (Fig. 1). The follicles were composed of endothelioid cells, numerous giant cells, and lymphocytes and plasma cells. In many of the follicles there were round yeast-like bodies, staining weakly with haematoxylin, and surrounded by clear spaces; they resembled Cryptococcus neoformans. The concentration of the yeast varied in different parts of the tissue from occasional cells to large aggregations, and were sometimes situated within giant cells (Fig. 2). The granulomatous reaction extended into the fatty connective tissue around the gland, and involved one small artery, projecting into its lumen (Fig. 3).

Two months later ancther lymph node enlarged at the same site as the first, and on this occasion fungus species identification was successful by culture of the biopsy specimen. At this time, too, a crusting ulcer, about $1 \mathrm{~cm}$. in diameter, developed on the lower lip. Scrapings from this contained yeasts with hyphae and Gram-positive cocci ; Candida albicans only was isolated in cultures. The lesion healed slowly without scarring when painted with gentian violet.

The patient was treated successively with potassium iodide, streptomycin, penicillin, aureomycin, and chloromycetin, but these failed to bring about any clinical improvement. Intravenous gentian violet was given but abandoned when it produced venous thrombosis. Sulphadiazine, however, appeared to reduce the pyrexia and produce both subjective and objective improvement. It produced a gain in weight of $6 \mathrm{lb}$. in three weeks, and the patient was able to get up again after several months in bed. Sulphadiazine was discontinued after $75 \mathrm{~g}$. had been given, but this was followed by deterioration in his condition. Further courses of sulphonamides were given with the same good response, but had to be abandoned when the total white cell count fell below 800 per c.mm.; a total of $645 \mathrm{~g}$. of sulphonamide drugs was given. The 


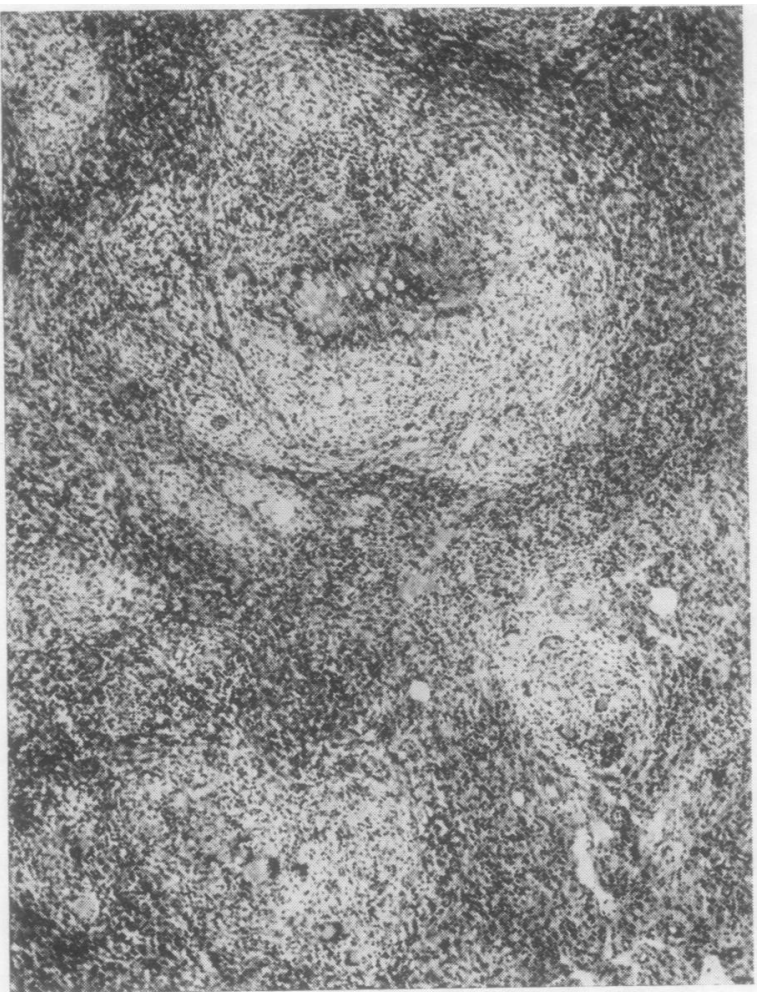

FIG. 1.-Section of a lymph node from the groin showing a follicular granulomatous reaction and encapsulated yeasts. Stained by haematoxylin and eosin $(\times 58)$.

general condition continued to deteriorate apart from one short spontaneous remission, and the patient died on October 10,1950, 13 months after the onset of symptoms.

Skin tests carried out with a suspension of a strain of Cryptococcus neoformans isolated from the lymph node were negative. Histoplasmin, 1 in 100 , coccidioidin, 1 in 1,000 , and blastomycin, 1 in 1,000 , also gave negative results. No complement-fixing antibodies were detected in the patient's serum when the homologous Cryptococcus neoformans suspension was used as antigen. Attempts to isolate Cryptococcus neoformans from the blood and the alimentary, respiratory, and urinary tracts were unsuccessful.

Post-mortem examination showed general wasting, a grossly enlarged liver (2,250 g.) and spleen (900 g.). These contained scattered areas of greyish infiltration surrounded by congestion. The para-aortic abdominal and posterior mediastinal lymph nodes were also enlarged. No abnormalities were found in the brain or spinal cord, lungs, heart, alimentary tract, kidneys, or endocrine glands. Mid-femoral bone marrow was red and hyperactive.

Histologically, Hodgkin's disease was present in the liver, spleen, and para-aortic glands. Normal tissue was replaced by lymphocytes intermingled with reticulum cells having large multiple or convoluted nuclei typical of "Sternberg Reed" cells (Fig. 4). No crypto cocci were found in these areas after prolonged searctor using special strains. The nodes from the groin in the region of the biopsies showed fibrosis only. Crypto coccus neoformans was not grown in cultures madefrom the liver, spleen, lung, brain, and abdominaf lymph nodes.

Mycological Investigations.- - In tissues, the yeast were surrounded by wide capsules, best demonstrate in smears by India ink or nigrosin, and staining easily with stains for mucopolysaccharides (periodic-aci $ॄ_{\bar{\psi}}$ Schiff method, toluidine blue, and mucicarmine). The Cryptococcus neoformans culture isolated from the gland biopsy was cream-coloured at first and becam\&o brownish and slimy later. Microscopy showed yeastos producing single blastospores but no hyphae ; abortivis hyphae were found only in the tissues. The cells were weakly Gram-positive, spherical and 3-10 $\mu$ i甲 diameter, with double contoured cell walls seen as. highly refractile rings in wet preparations. Capsuls formation was noted in old cultures.

On blood agar growth at $37^{\circ} \mathrm{C}$. was visible aftêf two days and reached maximal size, 2-3 mm., in two weeks. On Sabouraud's agar at $37^{\circ} \mathrm{C}$. growth was more rapid and was so mucoid that cultures flowed to dependent parts of the slopes. The yeast was reliz tively inert when submitted to fermentation tests; acid was produced without gas in peptone water containin $1 \%$ glucose and saccharose, but there was no fermer tation of other sugars (lactose, maltose, dulcite, ma

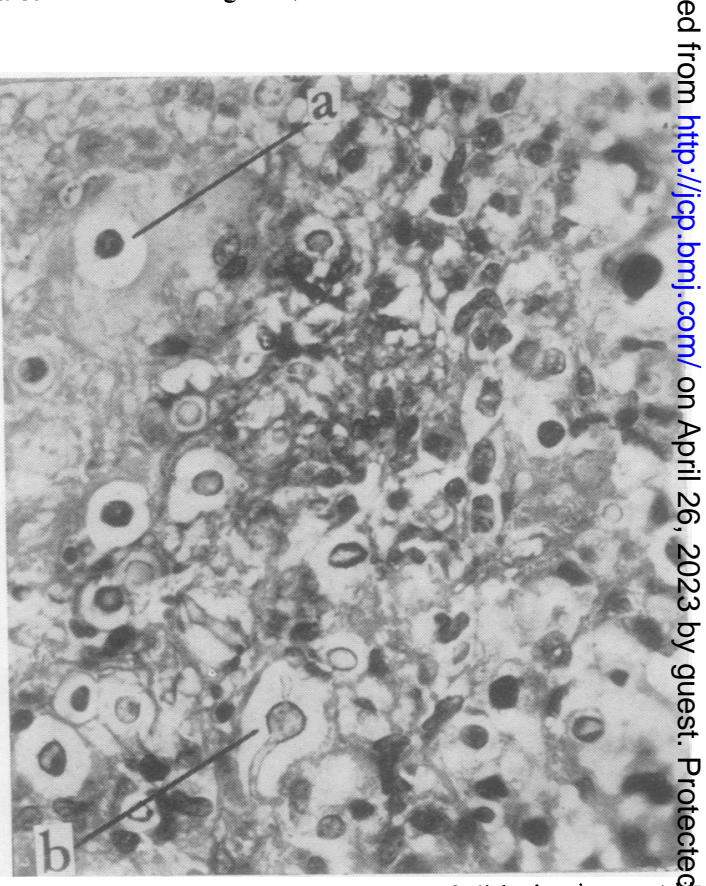

FIG. 2.-Section from the centre of a large follicle showing yeast-like organisms surrounded by clear zones. One cryptococcus $\left.f_{a}\right)$ lies within a giant cell; another (b) shows abortive hypha formation. Stained by Gram-carmalum. ( . 600). 


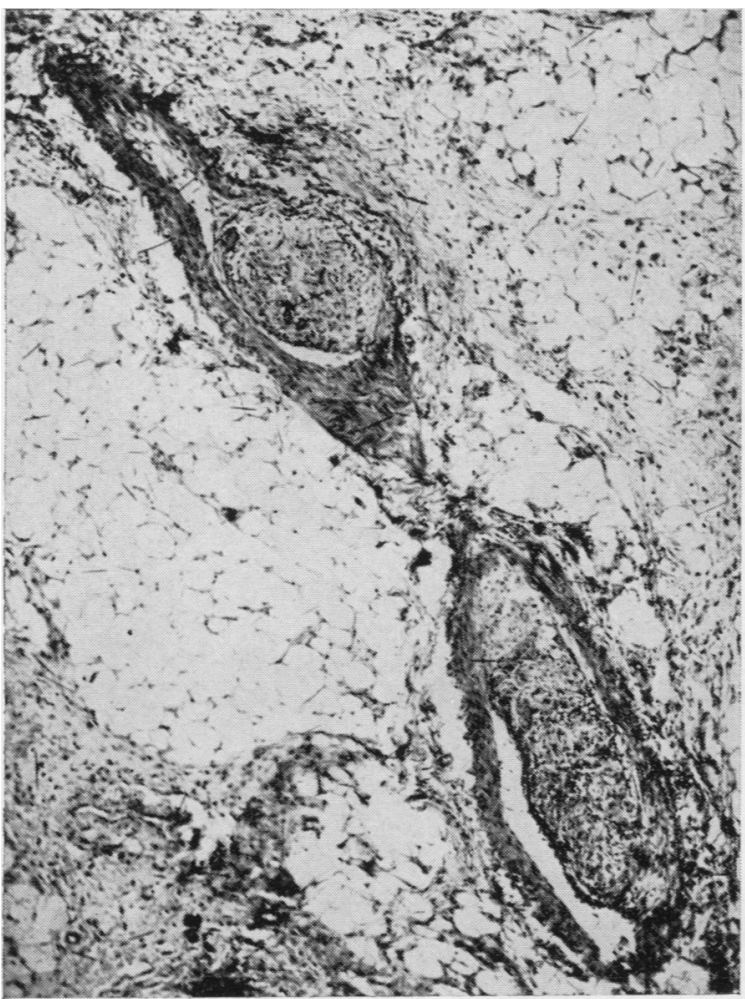

FIG. 3. Section showing a small artery near the node illustrated in Fig. 1 ; intimal follicles are seen bulging into its lumen. Stained by haematoxylin and eosin. $\times 58$ ).

nite, xylose, arabinose, inositol, dextrin, and salicin). Gelatin was not liquefied, and no hyphae were formed in corn meal agar.

Sensitivity tests showed no inhibition of growth by sulphonamides in concentrations of $20 \mathrm{mg} . \%$ of medium, nor by penicillin, chloromycetin, terramycin, aureomycin, or streptomycin at concentrations 10 times those obtainable in the body. Inhibition of growth by gentian violet occurred at a concentration of 1 in 10,000 .

The culture was virulent for mice. Three mice injected intraperitoneally with $0.2 \mathrm{ml}$. of a cell suspension from a young culture died between five and seven weeks with gelatinous nodules containing masses of cryptococci in the lungs, abdomen, and brain.

\section{Discussion}

The finding of Cryptococcus neoformans in the soil (Emmons, 1951) brings torulosis into line with other systemic mycoses, such as histoplasmosis, coccidioidomycosis, and aspergillosis, in which the causative organisms occur as saprophytes in nature. Cryptococcus neoformans is of low infectivity and human transmission of disease has not been reported.

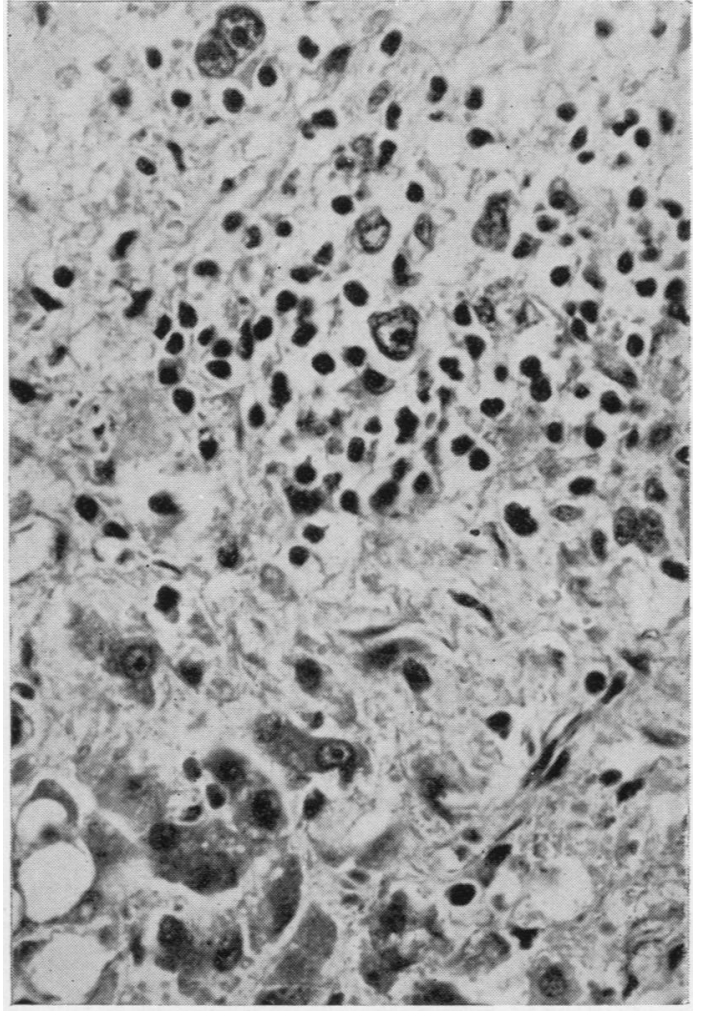

FIG. 4. Section of liver showing " Sternberg-Reed " cells in granulomatous infiltration. Stained by haematoxylin and eosin. $(\times 600$.)

In their exhaustive review of torulosis, Cox and Tolhurst (1946) note that roughly $8 \%$ of the reported cases were associated with Hodgkin's disease. It is suggested that prolonged nutritional deficiency in Hodgkin's disease is a factor in producing this striking association, for it is well known that in debilitated states non-pathogenic organisms and fungi may overcome the normal body defences and become invasive. In support of this, the work of Benham (1935) indicated that non-pathogenic strains of Cryptococcus neoformans would infect rats fed on a vitamin-deficient diet. There has been no convincing evidence that infection by this yeast can produce Hodgkin's disease. In the present case it is believed that torulosis was superimposed on a pre-existing lymphadenopathy. The infection was localized to the granulomatous lymph nodes of the right groin as far as could be established by histological and bacteriological investigations; no cryptococci were found in other regions affected by Hodgkin's disease. The presence of Candida albicans in the ulcer of the lip and in the sputum and faeces of 
this patient is considered to be without significance. In retrospect, the anaemia, leukopenia, pyrexia, and progressive debility are attributed to Hodgkin's disease and not to torulosis. It is unusual in torulosis for the brain and lungs to escape involvement as apparently occurred in this man, but the rapid progress of the reticulosis may have forestalled this. Evidence of primary infection was not found at necropsy. Treatment of torulosis is still empirical, for although sulphonamides in large and prolonged dosage are often temporarily successful the remissions so characteristic of this disease make evaluation of their efficacy impossible.

\section{Summary}

Infection with Cryptococcus neoformans in a man suffering from Hodgkin's disease is described.
The mycological investigations are presented and the interrelation between torulosis and Hodgkin's $\stackrel{?}{?}$ disease is briefly discussed.

I wish to thank Dr. Bruce Williamson for permission to use the clinical record, Dr. L. M. Franks for putting at my disposal the post-mortem material, and $\tilde{\omega}$ Dr. R. W. Riddell for his advice and encouragement. $\vec{O}$

\section{REFERENCES}

Benham, R. W. (1935). J. infect. Dis., 57, 255.

Cox, L. B., and Tolhurst, J. C. (1946). Human Torulosis. Melbourne⿻ University Press.

Emmons, C. W. (1951). J. Bact., 62, 685.

Gendel, B. R., Ende, M., and Norman, S. L. (1950). Amer. J. Med., V 9, 343 .

Symmers, W. St. C.( 1953). Lancet, 2, 1068. 